\title{
KAJIAN FAKTOR PEMBATAS DAN REKOMENDASI PERBAIKAN LAHAN UNTUK BUDIDAYA JAGUNG DI LAHAN RAWA PASANG SURUT TIPOLOGI C
}

\section{The Study of Limiting Factor and Land Improvment Recomendation for Corn Cultivation in Tidal Lowland C Thypologi}

\author{
Momon Sodik Imanudin'1), Abdul Majid2), Edi Armanto1) dan Miftahu12)
}

\author{
1) Dosen Jurusan Tanah Fakultas Pertanian Universitas Sriwijaya Kampus Unsri Indrlaya Km 32 Indralaya \\ Sumatera Selatan Telp. 62711580059 \\ 2) Peneliti Muda pada Pusadata Rawa dan Pesisir Sumatera Selatan Blok I 29 Perumahan Bukit
}

\begin{abstract}
The research aims to determine some limiting factor ragarding soil and water parameter for agriculture development in tidal lowland, farticulary for corn cultiation. The research method was survey and field experiment. The results showed that the main limiting factors were the depth of the pyrite layer and the status of groundwater table. Meanwhile, limiting factors for soil acidity and low fertility can be improved by liming and fertilizing. Improvements in water management and soil fertility have been able to create optimal corn crop production of 7 tonnes $a^{-1}$. However, in conditions where the dry period lasts $4-5$ months, the main limiting factor will appear which is caused by the oxidation of the pyrite layer. This happened because the groundwater table fell by more than $90 \mathrm{~cm}$. In this condition, corn production decreased by more than $50 \%$ and most of the planted area failed to harvest due to drought and poisoning. Farmers who succeed are those who plant earlier, namely in May. Meanwhile all the crops in July failed to harvest. The floodgate is not operated to hold water in the tertiary channel so that water loss is faster. The impact of groundwater in September drops below $90 \mathrm{~cm}$ and firit oxidation occurs. Therefore, the operation of the tertiary gate should be opened at high tide and closed at low tide. This operation continues until it has not entered the salt water (August). And entering the month of September when there was salt water intrusion, the tertiary gate were permanently closed. From the above conditions, in dry conditions for more than 4 months, the main recommendations are accelerating planting time, providing soil amendment materials and operating water gates with a retention option since April.
\end{abstract}

Keywords: Corn, limiting factor, tidal lowland, water management

\section{ABSTRAK}

Penelitian bertujuan untuk mengkaji beberapa faktor pembatas lahan yang selanjutnya disusun rekomendasi perbaikan, agar tanaman bisa tumbuh sesuai standar produksi. Metode penelitian adalah survai dan percobaan lapangan Hasil penelitian menunjukan faktor pembatas utama adalah kedalaman lapisan pirit dan status air tanah. Sementara faktor pembatas kemasaman tanah dan kesuburan yang rendah bisa diperbaiki dengan pengapuran dan pemupukan. Perbaikan tata air dan kesuburan tanah telah mampu menciptakan produksi optimal tanaman jagung 7 ton ha ${ }^{-1}$. Namun pada kondisi dimana kemarau selama $4-5$ bulan maka akan muncul faktor pembatas utama yang disebabkan oleh oksidasi lapiran pirit. Hal ini terjadi karena muka air tanah turun lebih dari $90 \mathrm{~cm}$. Pada kondisi ini produksi jagung menurun lebih dari $50 \%$ dan sebagian besar area tanam gagal panen karena kekeringan, dan keracunan. Petani yang berhasil adalah yang melakukan penanaman lebih awal yaitu bulan Mei. Sementara yang tanam Juli semua gagal panen. Pintu air tidak dioperasikan untuk menahan air di saluran tersier sehingga kehilangan air lebih cepat. Dampaknya air tanah pada bulan September turun dibawah $90 \mathrm{~cm}$ dan terjadilah oksidasi firit. Oleh karea itu operasi pintu sebaiknya dibuka pada saat pasang dan ditutup pada saat surut operasi ini berlansung sampai belum masuk air asin (Agustus). Dan memasuki bulan September dimana telah terjadi intrusi air asin, maka pintu air ditutup permanen. Dari kondisi diatas maka pada kondisi kemarau lebih dari 4 bulan, rekomendasi utama adalah percepatan waktu tanam, pemberian bahan pembenah tanah dan operasi pintu air dengan sistem retensi sejak bulan April.

Kata kunci: Jagung, faktor pembatas, rawa pasang surut, tata air mikro

\section{PENDAHULUAN}

Prospek usahatani tanaman jagung semakin baik. Berdasarkan data dari Kementrian Pertanian (2020) bahwa proyeksi kebutuhan jagung pada tahun 2020 untuk pabrik pakan sebesar 8.5 juta ton dan untuk peternak sebesar 3,48 juta ton. Angka kebutuhan jagung nasional sangat tinggi dilaporkan oleh Consumer News and Business Channel Indonesia (2020) bahwa perum BULOG akan mengimpor jagung sebanyak 200,000 ton. Jumlah tersebut untuk memenuhi kebutuhan industri pakan dan peternak mandiri.
Oleh karena itu dalam rangka kemandirian pangan, maka masih diperlukan upaya-upaya peningkatan produksi baik melalui perluasan area maupun intesifikasi lahan.

Dalam upaya pemenuhan target produksi tanaman jagung ada beberapa kendala terkait penyediaan lahan. Areal sawah irigasi semakin terbatas karena dipergunakan untuk pertanaman padi sawah disamping alihfungsi lahan ke pemukiman dan industri. Sementara lahan kering di luar Jawa lebih banyak dipergunakan untuk perkebunan. Oleh karena itu tidak ada jalan lain untuk menggunakan semaksimal mungkin lahan rawa pasang surut. Beberapa 
faktor pembatas sering ditemui dilapangan. Faktor pembatas ini seringkali menghambat pertumbuhan tanaman terganggu (Armanto et al., 2013) beberapa faktor pembatas utama adalah adanya lapisan pirit, ketergenangan, kekeringan dan faktor retensi hara. Namun sejauh ini melalui input teknologi faktor pembatas ini bisa diperbaiki. Hanya saja pengetahuan petani masih terbatas terutama dalam upaya menyesuaikan waktu tanam terhadap pola perubahan iklim (Imanudin et al., 2016). Faktor pembatas dalam budidaya tanaman di lahan rawa pasang surut sangat erat kaitannya dengan tipologi lahan. Areal tipologi lahan C dengan kondisi tidak menerima luapan air pasang untuk suplai air, seringkali memiliki produktivitas lebih rendah dibandingkan dengan tipologi A dan B (Suprianto et al., 2010). Masalah utama pada lahan tipologi C adalah kehilangan air berlebihan sehingga musim kemarau terjadi penurunan muka air yang dalam, mencapai batas kritis melebihi lapisan sulfat masam (Imanudin et al., 2019). Pada daerah rawa pasang surut perubahan muka air tanah sangat tergantung kepada input air terutama dari curah hujan (Rizzo et al., 2018).

Produktivitas lahan di daerah rawa pasang surut sangat dipengaruhi oleh masalah kondisi fisik lahan yang meliputi status air, dan kesuburan tanah. Sering kali tipologi lahan yang sama ternyata memiliki status air yang berbeda (Imanudin et al., 2017). Keragaman status air ini akan sangat berpengaruh terhadap froses fisik, biologi dan kimia tanah yang selanjutnya akan menentukan tingkat kesuburan tanah itu sendiri. Oleh karena itu kunci budidaya pertanian di rawa pasang surut adalah faktor pengendalian air (Schultz et al., 2015). Kedalaman air tanah ini harus dipertahankan barada di atas lapisan pirit untuk mengindari proses oksidasi lapisan pirit (Shamshuddin et al., 2014). Manakala terjadi peroses oksidasi pirit maka akan terjadi penurunan $\mathrm{pH}$ dan peningkatan Alumunium yang meracuni tanaman (Hadi, 2004). Permasalahan yang terjadi akibat proses pemasaman tanah adalah apabila senyawa atau unsur yang beracun tidak terbuang dari lingkungan perakaran, maka pertumbuhan tanaman terhambat, lahan kemudian menjadi lahan tidur. Kondisi ini akan menjadi pembatas utama yang sulit diperbaiki (Maftu'ah dan Susilawati, 2018).

Tujuan dari penelitian ini adalah untuk menemukan faktor-faktor pembatas dalam usaha budidaya tanaman jagung di lahan rawa pasang surut. Selanjutnya akan disusun rekomendasi perbaikan, sehingga proses budidaya tanaman bisa dilakukan dengan produksi tanaman yang masih menguntungkan.

\section{BAHAN DAN METODE}

\section{Tempat dan Waktu}

Penelitian ini telah dilaksanakan di Kebun Jagung masyarakat di Desa Bangun Sari dan Desa Mulya Sari Kecamatan Tanjung Lago Kabupaten Banyuasin. Area lahan tergolong lahan pasang surut tipologi $\mathrm{C}$ yaitu lahan yang tidak bisa menerima luapan air pasang. Jadi lahan tidak dapat suplai air irigasi pasang secara gravitasi, sehingga memiliki karakter seperti lahan tadah hujan. Analisis sampel tanah dilakukan di Laboratorium kimia, biologi, dan kesuburan tanah, Fakultas Pertanian Universitas Sriwijaya, Indralaya. Penelitian ini dilaksanakan pada bulan September 2018 sampai Mei 2019. Untuk melakukan validasi usaha tani, pengamatan budidaya tanaman juga dilakukan di musim tanam tahun 2019.

\section{Alat dan Bahan}

Adapun Alat-alat yang digunakan dalam penelitian ini adalah 1) alat tulis, 2) alat- alat analisi di laboratorium, 3) Bor belgie, 4) cangkul, 5) GPS, 6) meteran, 7) Munsell Soil Color Charts, 8) pisau lapangan

Adapun bahan-bahan yang digunakan dalam penelitian ini adalah 1) air, 2) bahan-bahan analisis di laboratorium, 3) kertas label, 4) kantong plastik, 5) karet, 6) sampel tanah

\section{Metode Penelitian}

Metode yang digunakan dalam penelitian ini adalah metode survei pada tingkat intesif dengan observasi langsung ke lapangan menggunakan peta berskala 1: 3000 dan luas Areal Demplot sebesar \pm 16 ha. Sementara pengamatan hidrologi dilakukan pada 3 petak pewakil seluas 3 ha (Gambar 1).

Pengambilan contoh tanah dilakukan dengan pengeboran sampai kedalaman $30 \mathrm{~cm}$. Pengambilan dilakukan pada area monitoring lahan seluas 3 ha, dengan jumlah sampel adalah 2 buah pada setiap hektar, Contoh tanah untuk analisis kimia yang meliputi parameter yang berkaitan erat dengan kesesuaian lahan. Parameter tanah yang diamati berupa, Tekstur tanah, Tingkat kemasaman tanah (pH), Kapasitas Tukar Kation (KTK), Kandungan Corganik, penetapan kadar Nitrogen. Budidaya tanaman jagung dilakukan pada petak tersier dengan luas 16 ha. Tabel 1 menunjukkan kegiatan usaha tani jagung.

Tabel 1. Informasi mengenai usaha tani Jagung di Desa Bangun Sari (Tipe lupan lahan C)

\begin{tabular}{rcc}
\hline No. & Komponen Usaha Tani & Perlakuan \\
\hline 1 & Varietas & Pioner 32, bisi 18 \\
2 & Pupuk Urea & $400 \mathrm{~kg} \mathrm{ha}^{-1}$ \\
3 & Pupuk ponska (NPK) & $400 \mathrm{~kg} \mathrm{ha}^{-1}$ \\
4 & Pengendalian hama & kimia \\
\hline
\end{tabular}

Sumber: data primer (2018)

Dinamika muka air tanah diamati dengan mengggunakan pipa paralon berlubang (Gambar 2). Pengamatan dilakukan setiap hari jam 07.00 pagi. Untuk pengamatan tinggi muka air di saluran dilakukan dengan pemasangan papan piescall yang dibuat dari kayu/ papan dengan lebar $10 \mathrm{~cm}$ dan tinggi $200 \mathrm{~cm}$ yang di cat putih dan di beri tulisan berupa angka dari $0-200 \mathrm{~cm}$, dan di tanam di dalam saluran tersier diamati selama 2 bulan setiap pukul 07.00 pagi.

\section{Analisis data}

Data yang telah di dapatkan dari lapangan dan laboratorium akan di olah berdasarkan sifat fisik dan kimia tanah yang akan di sajikan dalam tabel dan deskriptif, dan melihat kesesuaian lahannya berdasarkan kriteria sifat fisik dan kimia. Selanjutnya pengamatan pertumbuhan tanaman jagung juga di lihat pada kondisi Curah hujan berlebih tahun 2018 dan terbatas di tahun 2019. 
PETA PENGAMBILAN TITIK SAMPEL DI DESA BANGUN SARI

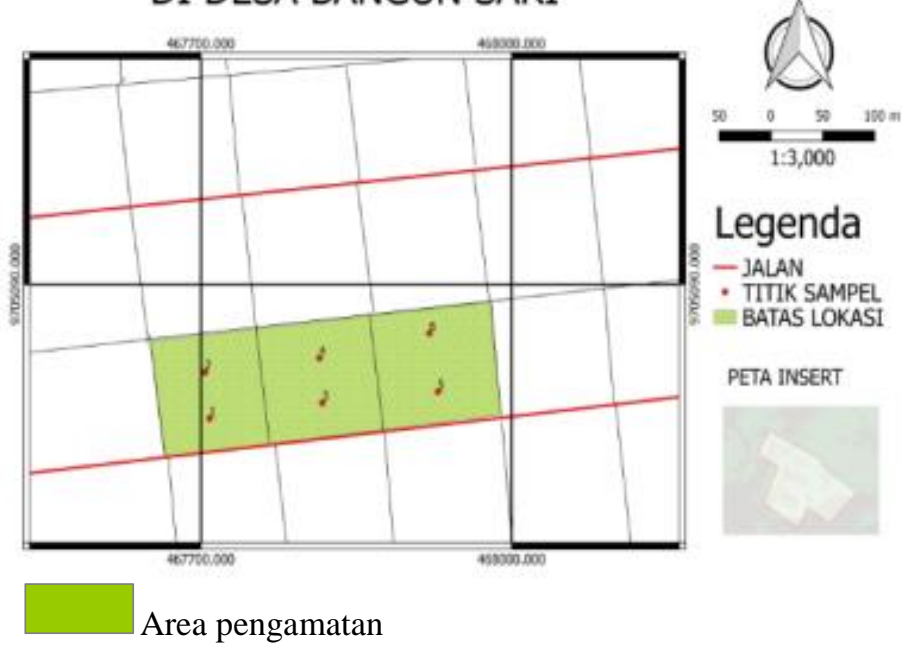

Gambar 1. Penataan lahan di area percobaan di Desa Bangun Sari

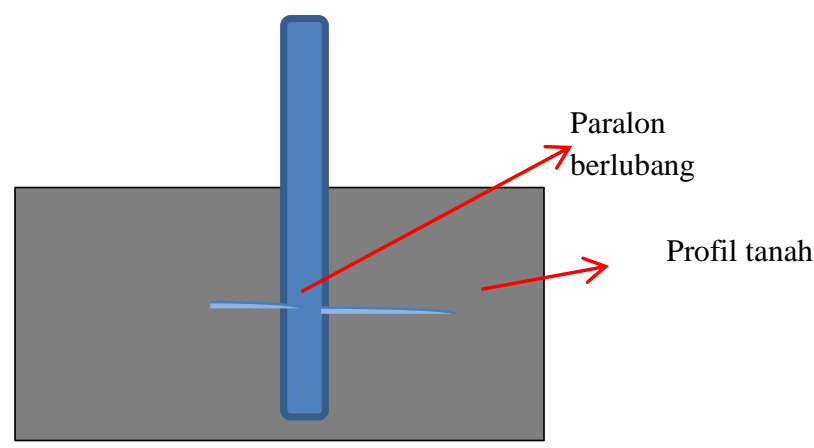

Gambar 2. Pipa paralon yang ditanam untuk mengamati muka air tanah.

\section{HASIL DAN PEMBAHASAN}

\section{Gambaran Umum Area Penelitian}

Penelitian dilakukan di Desa Bangun Sari terletak di Kecamatan Tanjung Lago Kabupaten Banyuasin III. Desa Bangun Sari merupakan daerah pasang surut letaknya di Primer 17 jembatan 5. Jumlah penduduk 3,120, terdiri dari laki-laki 1,579 orang dan perempuan 1.541 orang dengan jumlah Kepala Keluarga (KK) 825 KK. Desa Bangun Sari banyak dihuni oleh warga transmigrasi yang berasal dari daerah Jawa Barat, Jawa Tengah, dan Bali. Mayoritas Warga Desa Bangun Sari bekerja sebagai petani, seperti petani karet, Padi, Jagung dan Kelapa Sawit. Warga Desa Bangun Sari ini tidak hanya bergantung pada hasil lahan pertanian saja. Beberapa warga yang memanfaatkan lahan kosong di sekitar rumahnya ditanami kelapa dan kolam ikan yang nantinya akan didistribusikan kepada pedagang yang ada di Kota Palembang dan di pasar induk Tanjung Lago.

Secara tipologi lahan, areal pertanian termasuk edalam tipologi lahan C. Lahan ini tidak menerima luapan air pasang, baik pasang besar maupun kecil. Air pasang hanya bisa masuk ke saluran tersier untuk menjaga kedalaman air tanah. Lahan bersifat tadah hujan, sehingga curah hujan merupakan faktor penting untuk menyediakan air bagi tanaman.

Sistem tata air di area direncanakan bekerja berdasarkan konsep aliran satu arah (one way flow system) di mana air pasang masuk melalui saluran Primer dan terus ke Sekunder pemberi (SPD), dan masuk ke tersier pemberi yang akhirnya mengaliri lahan usaha tani. Pada kondisi air berlebih (musim hujan) air dari lahan akan keluar melalui tersier pembuangan dan terus menuju sekunder pembuangan (SDU) yang selanjutnya menuju ke saluran primer. Konsep ini akan berjalan dengan baik bila sistem tata air dilengkapi dengan pintu pengendali. Kenyataan yang terjadi saat ini di lapangan, saluran SPD dan SDU keduanya berfungsi sebagai saluran untuk memasukkan dan mengeluarkan air. Sehingga konsep aliran satu arah di lapangan tidak lagi berjalan. Namun demikian keuntungan aliran dua arah ini saluran mendapatkan air yang cukup, tidak ada air tertahan, sehingga proses sedimentasi lebih lambat.

Saluran sekunder dibagi menjadi dua saluran yaitu saluran pemberi yang melintasi perkampungan dinamakan Sekunder Pemberi (SPD) dan saluran pembuangan Sekunder Pembuangan (SDU) ini berada di batas lahan usaha II. Saluran tersier dibangun untuk mengalirkan atau membuang air dari dan ke saluran sekunder. Saluran tersie ini melayani area seluas 16 ha. Saluran ini harus selalu ada air meskipun kondisi kemarau, gunanya untuk menjaga kedalaman muka air tanah agar tidak mengalami penurunan cepat. Gambar 3 adalah kondisi saluran tersier. 


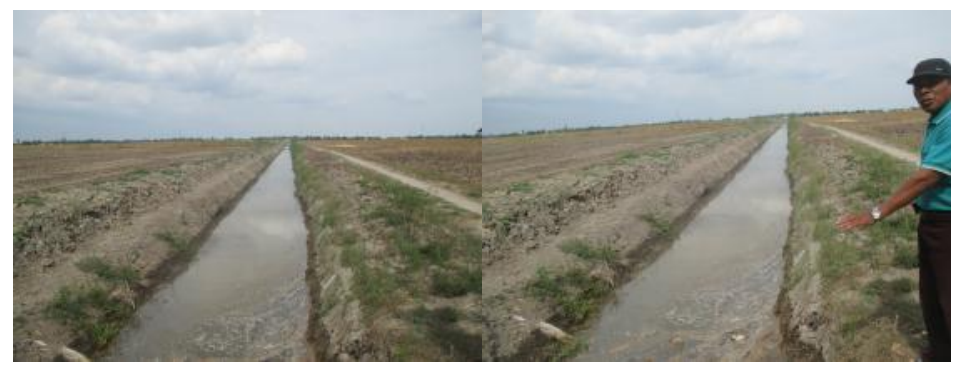

Gambar 3. Kondisi saluran tersier di lahan pasang surut delta Telang II

\section{Kondisi curah hujan dan muka air tanah}

Dinamika curah hujan bulanan pada tahun 2018 dan 2019 dapat dilihat pada Gambar 3. Curah hujan pada tahu 2018 lebih tinggi dibandingkan dengan tahun 2019. Curah hujan merupakan faktor utama dalam komponen keseimbangan air di lahan tipologi C. Sehingga pada budidaya tanaman jagung tahun (2018), dimana hujan bulanan lebih dari $120 \mathrm{~mm}$ lebih dari 5 bulan, maka tanaman tidak memerlukan suplai air dari irigasi pompa. Suplai air dari irigasi pasang pada lahan ini tidak bisa. Air pasang hanya mampu mengisi saluran tersier. Sehingga bila saluran tersier penuh air maka air tanah di lahan tidak cepat turun. Dan bila hujan turun maka akan terjadi kenaikan muka air tanah. Konsep ini membuat lahan seperti sistem tadah hujan. Petani cukup melakukan penutupan pintu air di saluran untuk mempertahankan muka air tanah dan menahan air hujan di petak tersier. Namun kondisi sebaliknya terjadi di tahun 2019 dimana bulan kering lebih banyak $(<120 \mathrm{~mm})$, yaitu sejak bulan Agustus tidak turun hujan, yang menyebabkan lahan kekeringan.

Kondisi ini jelas curah hujan merupakan faktor pembatas utama pengembangan lahan pasang surut yang harus dikelola. Kebutuhan untuk evapotraspirasi jagung dan perkolasi adalah $5 \mathrm{~mm}$, maka dalam sebulan setidaknya diperlukan air sebanyak $150 \mathrm{~mm}$. Sehingga tahun 2019 terjadi defisit air selama 6 bulan yaitu sejak bulan Juni sampai November.

Perbedaan muka air tanah antara musim hujan dengan awal musim kemarau (Juni) bisa mencapai 50$60 \mathrm{~cm}$. Ini berarti bila tidak ada usaha konservasi air maka memasuki bulan Juni air tanah berada 70-80 cm dibawah permukaan tanah (asumsi air tanah berada pada level $20 \mathrm{~cm}$ di musim hujan). Ditambahkan oleh Imanudin et al. (2010) pada tanah pasang surut tipologi $\mathrm{C}$, muka air tanah di puncak musim kemarau bisa turun sampai kedalaman 100 $\mathrm{cm}$. Kondisi ini berbahaya karena kebutuhan air tanaman tidak bisa dipenuhi oleh air kafiler dan akan terjadi oksidasi lapisan firit yang menghasilkan kemasaman tanah. Pada kondisi ini menyebabkan tanaman mengalami gangguan serius bahkan bisa mati.

Fluktuasi muka air tanah merupakan parameter yang paling utama dalam budiday tanaman di lahan rawa. Keberadaan muka air tanah sangat penting untuk memenuhi kebutuhan air tanaman. Pada lahan pasang surut muka air di saluran tersier sangat mempengaruhi keberadaan air tanah di petakan lahan. Selain itu kondisi curah hujan yang jatuh juga akan sangat berpengaruh. Gambar 3. Menunjukan kondisi dinamika muka air di lahan dan saluran. Pada kondisi musim kemarau bulan Oktober terlihat bahwa bila air di saluran tersier turun (tinggal $20 \mathrm{~cm}$ ) maka muka air tanah di lahan turun sampai sekitar $70-80 \mathrm{~cm}$ dari permukaan tanah. Sementara pada bulan November terjadi kenaikan muka air di saluran dimana air pada level $60 \mathrm{~cm}$ menyebabkan naiknya muka air tanah pada level $30-40 \mathrm{~cm}$ dibawah permukaan tanah. Ini jelas bahwa untuk menjaga muka air tanah di lahan pada kondisi sesuai pertumbuhan tanaman maka muka air di saluran harus berada minimal di level $60 \mathrm{~cm}$. Senada dengan hasil penelitian Hafiyyan et al. (2017) yang menyatakan bahwa pola dinamika muka air tanah sangat tergantung dengan muka air di saluran. Sehingga untuk menjaga muka air tanah tidak cepat turun maka air di saluran tersier harus selalu ada. Oleh karena itu jelas bahwa peran pengelolaan elevasi muka air pada saluran tersier sangat penting dalam merencanakan pengelolaan air di blok tersier. Kondisi ini disebabkan porositas pada atas tanah pasang surut relative tinggi, terutama pada lahan tipologi $\mathrm{C}$ apalagi pada lahan gambut. Ditambahkan oleh Imanudin et al. (2019) bahwa pada kondisi tanah dengan kehilangan air tinggi maka diperlukan penahanan air total menjelang musim kemarau dengan sistem sekat atau stoplog di ujung saluran tersier. Untuk itu diperlukan model pintu air stoplog atau sorong.

\section{Analisis Faktor Pembatas}

Untuk tumbuh dan berkembang tanaman memerlukan lingkungan dan biofisik lahan yang sesuai dengan syarat tumbuhnya. Apalagi untuk memacu produksi, diperlukan usaha lebih dalam peningkatan lingkungan yang sesuai. Daerah rawa memiliki faktor pembatas yang relative lebih banyak dibanding dengan lahan kering. Faktor pembatas utama adalah pembatas yang sulit di perbaiki dan sangat berpengaruh kepada produksi. Sementara pembatas sementara adalah bisa diperbaiki dengan teknologi.

Tabel 2 menunjukkan komponen utama karakterstik lahan dan air yang bisa menjadi faktor pembatas dalam usaha tani jagung. Komponen kesuburan tanah yang sangat berpengaruh adalah tingkat kemasaman tanah dan ketersediaan hara makro tanah. $\mathrm{pH}$ tanah tergolong sangat masam pada kondisi kering dimana muka air tanah melebih lapisan pirit $(>80 \mathrm{~cm})$, dan ketersedian hara makro seperti Nitrogen, Kaliun rendah. Ini sejalan dengan rendahnya kandungan bahan organik. Namun demikian faktor kesuburan tanah ini bisa diatasi dengan pemberian kapur, pupuk kandang, biochar, dan pupuk kimiawi seperti urea, SP36 dan Kalium. Penelitan Zuraida dan Rosita (2010) pada budidaya jagung di lahan pasang surut menunjukan hasil yang baik dengan produksi rata-rata 5 ton ha $^{-1}$. Faktor pembatas terkait lahan dan air bisa diatasi dengan teknologi. Kesuburan tanah yang rendah bisa diatasi dengan 
pemberian pupuk Urea, SP36 dan $\mathrm{KCl}$ dengan dosis berturut turut adalah 200;100; $100 \mathrm{~kg} \mathrm{ha}^{-1}$ (Hadi, 2004). Sementara itu dengan pengelolaan yang baik secara nasional produksi jagung potesial bisa mencapai 8 ton ha ${ }^{-1}$ (Nurdin, 2012). Tabel 3 adalah produksi yang dicapai di desa Bangun Sari pada musim tanam 2018.
Penelitian Sagala (2010) menunjukkan bahwa penggunaan dosis kapur setara 2.5 ton $\mathrm{ha}^{-1}$ untuk dikawasan delta Telang II sudah cukup untuk menaikkan $\mathrm{pH}$ tanah sesuai pertumbuhan tanaman menjadi 5.36.

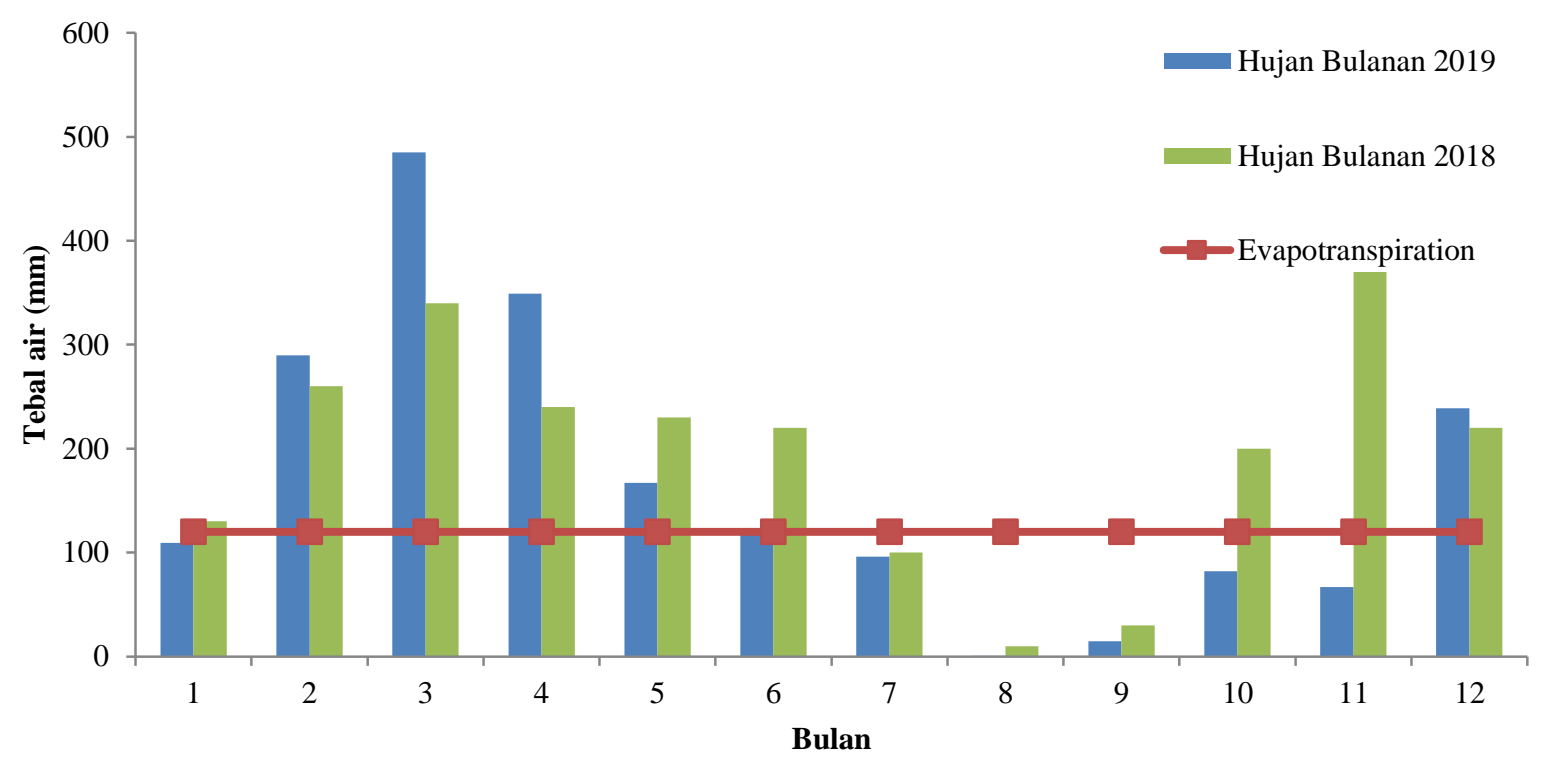

Sumber: BMKG, (2019)

Gambar 2. Curah hujan pada kondisi iklim normal (2018) dan kering (2019)

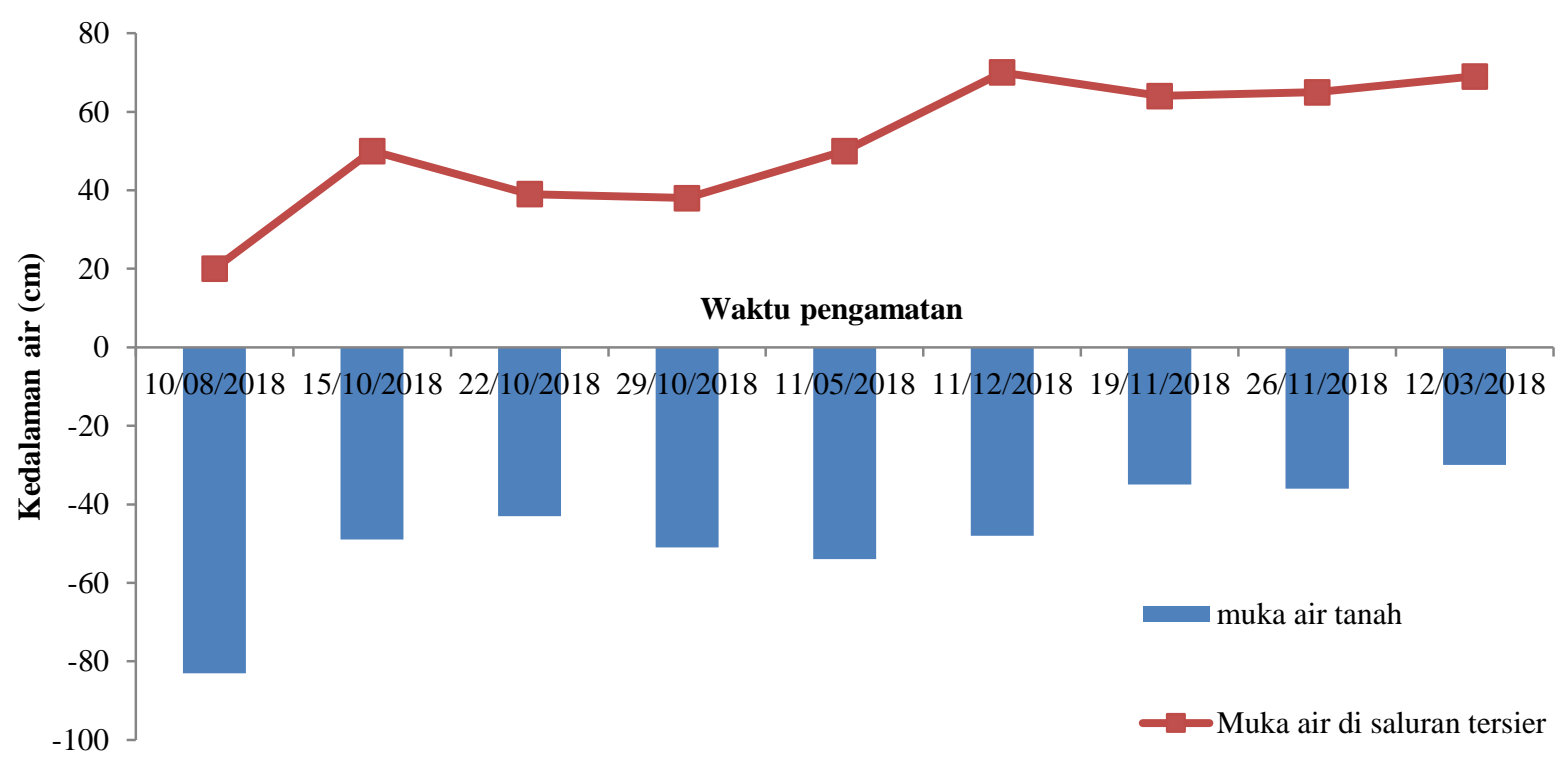

Gambar 3. Dinamika muka air tanah dan air di saluran

Tabel 2. Faktor pembatas dan usaha perbaikan dalam budidaya jagung di pasang surut

\begin{tabular}{lll}
\hline No & \multicolumn{1}{c}{ Faktor Pembatas } & \multicolumn{1}{c}{ Rekomendasi Perbaikan } \\
\hline 01 & $\begin{array}{l}\text { Tanah: Kemasaman tinggi, Kelarutan Alumunium, } \\
\text { Besi tinggi; Status hara rendah NPK, KTK endah }\end{array}$ & $\begin{array}{l}\text { Perbaikan tata air mikro, pengapuran, pemberian bahan pembenah tanah seperti biochar, zeolit, } \\
\text { urine sapi, pemupukan berimbang dan pemberian pupuk biologis }\end{array}$ \\
\hline 02 & Oksidasi Pirit & $\begin{array}{l}\text { Menjaga kedalaman air tanah berada pada 50-60 cm, dengan operasi pintu retensi (penahanan); } \\
\text { konsep panen hujan, dan memasukan air pasang (suplesi) sampai bulan Juni }\end{array}$ \\
\hline 03 & $\begin{array}{l}\text { Keracunan besi, dan tingginya Alumunium di zona } \\
\text { akar }\end{array}$ & $\begin{array}{l}\text { Pencucian di lahan dan pengelontoran air di saluran pada saat awal musim penghujan dan } \\
\text { periode tanam padi. Tata air mikro harus di bangun, dan kapasitas saluran tersier harus } \\
\text { ditingkatkan }\end{array}$ \\
\hline 04 & Intrusi air asi Kemarau panjang & $\begin{array}{l}\text { Pintu tersier ditutup permanen menjelang pertengahan bulan Agustus sampai bulan } \\
\text { November. }\end{array}$ \\
\hline
\end{tabular}


Tingkat kemasaman juga merupakan faktor pematas. Pengaruh $\mathrm{pH}$ ini terutama berkaitan dengan ketersediaan unsur-unsur hara di dalam tanah, terutama unsur hara fosfor $(\mathrm{P})$. Unsur hara $\mathrm{P}$ kurang tersedia pada $\mathrm{pH}$ tanah antara 3-4. Pada tanah-tanah masam, unsur hara $\mathrm{P}$ terfiksasi dan tidak tersedia bagi tanaman. Pada tanah masam, unsur hara $\mathrm{P}$ difiksasi oleh aluminium dan besi. Oleh karena itu untuk meningkatkan produksi lahan masih memerlukan pengapuran, meskipun dengan dosis rendah. Penelitian Suriadikarta (2005) menyatakan pemberian batuan phospat (Rock Phospat) dengan dosis $200 \mathrm{~kg} \mathrm{ha}^{-1}$ mampu menggantikan kebutuhan $100 \mathrm{~kg}$ SP36 ha-1.

Produksi jagung pada kondisi iklim curah hujan normal sangat baik (Tabel 3), ini sudah mendekati target produksi nasional yang 8 ton $\mathrm{ha}^{-1}$. Oleh karena itu lahan ini memiliki potensi yang besar dan input teknologi yang ditambahakan tidak terlalu besar untuk bisa melampaui target produksi 8 ton/ha.

Tabel 3. Produksi jagung pada kondisi iklim normal di daerah rawa pasang surut tipologi $\mathrm{C}$

\begin{tabular}{ccc}
\hline Lokasi & Bagian Utara & Bagian Selatan \\
\hline Petak 1 & 8.1 & 8.1 \\
Petak 2 & 8.1 & 7.0 \\
Petak 3 & 7.1 & 8.0 \\
Petak 4 & 7.0 & 7.0 \\
Petak 5 & 7.1 & 7.1 \\
Petak 6 & 8.0 & 7.9 \\
Petak 7 & 7.1 & 7.1 \\
Petak 8 & 6.9 & 7.2 \\
\hline Rata-rata produksi & $=7.4$ ton ha & \\
\hline
\end{tabular}

Sumber Data Primer

Upaya perbaikan sifat fisik tanah yaitu dengan meningkatkan kemampuan struktur tanah di zona akar. Salah satu upaya yang bisa dilakukan adalah dengan pemberian bahan pembenah tanah (bioachar). Biochar adalah residu pirolisis berbentuk arang yang memiliki kandungan karbon tinggi. Biochar dapat memperbaiki sifat fisik, kimia dan biologi tanah, serta berpotensi bisa menurunkan emisi GRK. Hasil penelitian Annisa (2012) pemberian Biochar sekam padi yang dikombinasikan dengan kompos multiorganik di lahan sulfat masam dapat mengefisienkan penggunaan pupuk buatan NPK sebesar $50 \%$. Ditambahkan penelitian aplikasi biochar sebesar $2 \mathrm{t}$ $\mathrm{ha}^{-1}$ dan $4 \mathrm{t} \mathrm{ha}^{-1}$ mampu mengurangi penggunaan buatan pada tanaman jagung. Hasil panen pada kombinasi perlakuan biochar $4 \mathrm{t} \mathrm{ha}^{-1}$ dan NPK $180 \mathrm{~kg} \mathrm{ha}^{-1} 14.20 \mathrm{t} \mathrm{ha}^{-1}$ meningkat $12.67 \%$ dari kombinasi perlakuan biochar $0 \mathrm{t}$ ha1 dan NPK $300 \mathrm{~kg} \mathrm{ha}^{-1}$ dengan produksi $12.66 \mathrm{t} \mathrm{ha}^{-1}$ dan meningkat $1.36 \%$ dari kombinasi perlakuan biochar $2 \mathrm{t} \mathrm{ha}^{-1}$ dan NPK $300 \mathrm{~kg} \mathrm{ha}^{-1}$ dengan produksi $14.01 \mathrm{t} \mathrm{ha}^{-1}$. Penelitian Indriyati dan Anas (2013) inovas baru perbaikan kesuburan tanah adalah dengan pemberian zeolit-urine dengan takaran 2000 ppm nyata meningkatkan tinggi tanaman jagung, bobot kering bagian atas tanaman, serapan $\mathrm{N}$ akar, dan KTK tanah.

\section{Evaluasi Tinggi Muka Air Tanah Tahun 2019}

Hasil kajian dilapangan dilakukan, pengukuran kedalaman muka air tanah pada tanggal 30 September 2019 muka air tanah sudah sangat turun jauh bahkan sudah menyentuh lapiran pirit yaitu pada kedalaman $90 \mathrm{~cm}$ dibawah permukan tanah (Gambar 5). Pengamatn muka air dapat dilihat pada Gambar 5. Pada kondisi ini pertumbuhan tanaman jagung sudah terganggu dan beberapa tempat sudah mengalami kekringan, dan bahkan gagalan panen. Kabanyakan tanaman jagung yang mengalami kekurangan air adalah yan ditanam pada bulan Juli 2019. Dilaporkan oleh Bakri et al. (2015) bahwa pada kondisi kemarau muka air tanah optimum untuk pertumuhan tanaman jagung adalah 40-50 cm dibawah permukaan tanah. Oleh karena itu pada kondisi muka air tanah melebih angka $80 \mathrm{~cm}$ jelas tanaman memerlukan suplai air tambahan dari irigasi. Penelitian pada beberapa tanaman di Argentina secara umum kontribusi dari air tanah adalah berkisar antara 12$30 \%$ dari total kebutuhan air tanaman bila muka air tanah berada pada kedalaman 1.5m (Mensegue et al., 2015). Sementara bila muka air tanah berada dikisaran $40-50 \mathrm{~cm}$, untuk tanaman jagung di lahan rawa tidak diperlukan suplai air tanmbahan Pergerakan air kafiler sudah cukup untuk pemenuhan kebutuhan evapotraspirasi tanaman (Imanudin et al., 2019). Namun bila muka air tanah berada di angka $100 \mathrm{~cm}$ dari permukaan tanah maka pergerakan air kafiler hanya mampu mensuplai $41 \%$ dari kebutuhan evapotranspirasi tanaman (Gao et al., 2017). Dilaporkan oleh Rizzon et al. (2018) bahwa budiya produksi jagung di Amerika pada lahan dengan muka air tanah dangkal memiliki produksi lebih tinggi dibandingkan di lahan kering.

Kondisi lingkungan tata air sangat mempengaruhi pertumbuhan dan produksi tanaman. Sebab selain air, tanaman juga membutuhkan udara dalam tanah. Bila persediaan udara dalam tanah tidak mencukupi dapat merugikan tanaman. Keadaan lingkungan tanah dipengaruhi oleh berbagai faktor seperti sifat kimia dan kedalaman muka air tanah. Pada kondisi kedalaan air tanah diatas $90 \mathrm{~cm}$, maka ronga-ronga tanah di zona akar lebih banyak terisi udara. Gerakan air secara kafileritas tidak cukup untuk memenuhi kebutuhan evapotransfirasi tanaman. Ditambah kondisi peningkatan kemasaman tanah akibat oksidasi pirit. Sebagian besar lahan memiliki kedalaman pirit antara 80-100 cm (Imanudin et al., 2017), sehingga dapat diduga oksidasi sebagian sudah terjadi di lapisan sulfat masam. Oleh karena itu, tanaman tidak semata kekurangan air, tetapi juga terjadi akibat keracunan logam berat $\mathrm{Fe}$ dan $\mathrm{Al}$ sebagai akibat penurunan $\mathrm{pH}$ tanah akibat dari oksidasi pirit. 

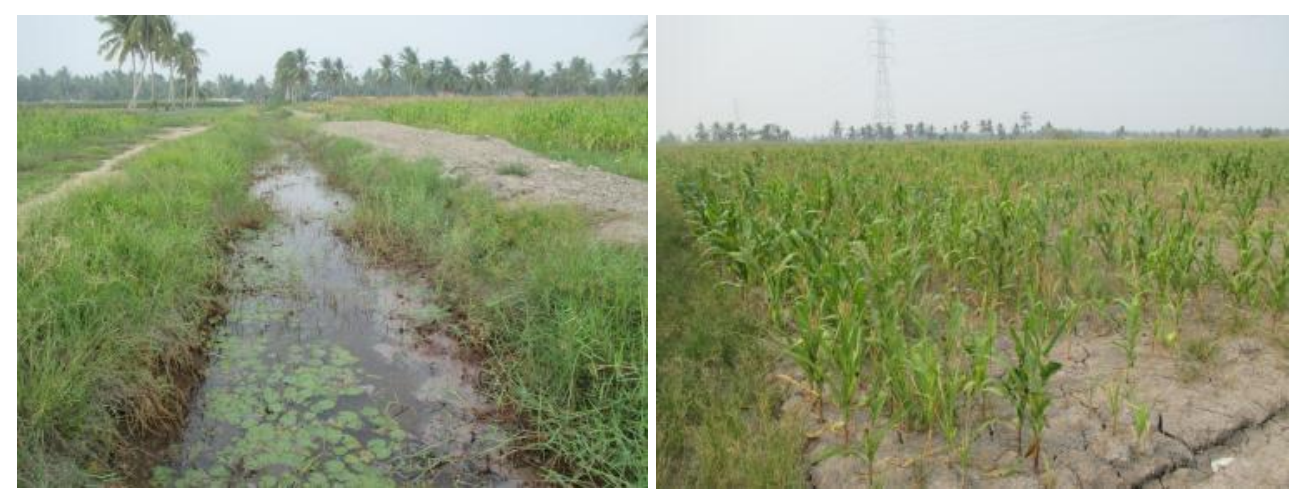

Gambar 4. Kondisi saluran dan tanaman jagung yang kekeringan September 2019.

\section{Manajemen Operasi Tata Air}

Kunci suskes keberhasilan budidaya tanaman di rawa pasang surut adalah bagaimana petani bisa mengatur muka air di saluran tersier. Untuk itu diperlukan bangunan pengatur muka air yang harus di pasang di setiap muara saluran tersier. Gambar 5 menunjukkan bangunan pintu ait tipe sorong yang di hibahkan kepada petani. Manajemen operasi tata air sangat tergantung kepada tujuan pengelolaan air. Pada saat budidaya tanaman yang menginginkan kondisi kering maka lahan harus tidak boleh tergenang, muka air tanah harus diturunkan dibawah jona akar, yaitu pada kedalaman 40-50 $\mathrm{cm}$ dibawah permukaan tanah. Oleh karena itu tujuan pengelolaan air di awal pertumbuhan adalah drainase maksium. Pada kondisi ini operasi pintu kelep diletakan di depan sehingga mampu menahan air pasang dan mengeluarkan air pada saat surut (Gambar 5).

Untuk menggantikan pintu kelep tipe fiber yang mahal maka dibuat pintu sorong dari bahan kayu. Pintu ini dibentuk dengan sangat sederhana, ada pegangan untuk menutup dan mengangkat. Fungsi fintu ini hanya dua yaitu untuk membuka artinya memasukan air, dan menutup artinya menehan air. Petani bisa membuat sendiri dengan bahan yang tersedia di lokasi, sehigga mudah dan murah. Namun kelemahannya adalah oprasi pintu harus sering dilakukan, sehingga membutuhkan lebih waktu dan tenaga. Gambaran pintu air tipe sorong dapat dilihat pada Gambar 6.

Memasuki bulan Mei air sudah berkurang dan pada bulan Juni lahan sudah mengalami deficit air. Pada tahun 2019 lahan mengalami masa kemarau sejak bulan Juni sampai Oktober, sehinga ada 5 bulan periode kekurangan air. Suplai air pada bulan September sudah tidak bisa dilakukan, karena air pasang sudah mengandunga air asin. Oleh karena itu petani di ahir bulan Mei sudah harus menutup pintu secara permanen untuk menyimpan air di saluran tersier. Saluran tersier harus di fungsikan sebagai long storage. Gambar 6, menunjukkan petani sedang mengoperasikan pintu sorong untuk ditutup permanen. Tujuannya adalah untuk menahan air hujan agar tidak terbuang melalui proses air surut. Hasil kajian dilapangan menunjukkan pada kondisi bulan basah manajemen operasional tata air dilakukan dengan tujuan pembuangan.

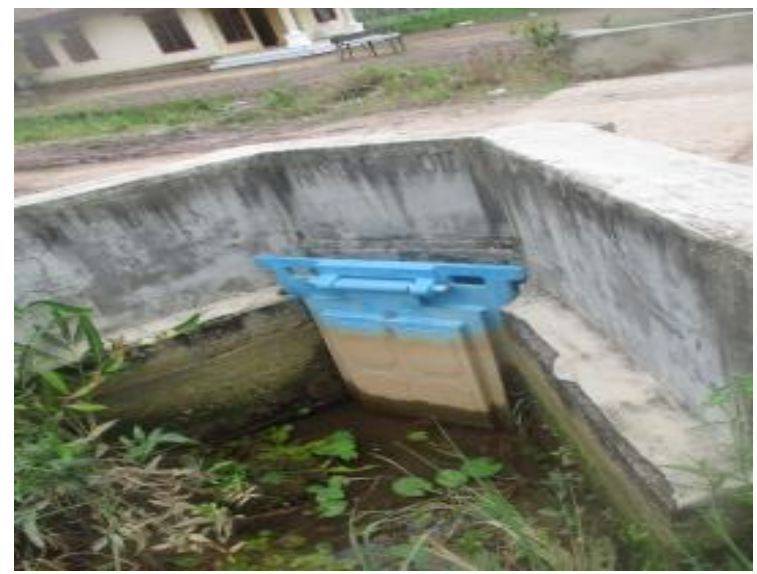

Gambar 5. Operasi pintu kelep untuk pembuangan air di awal pertumbuhan
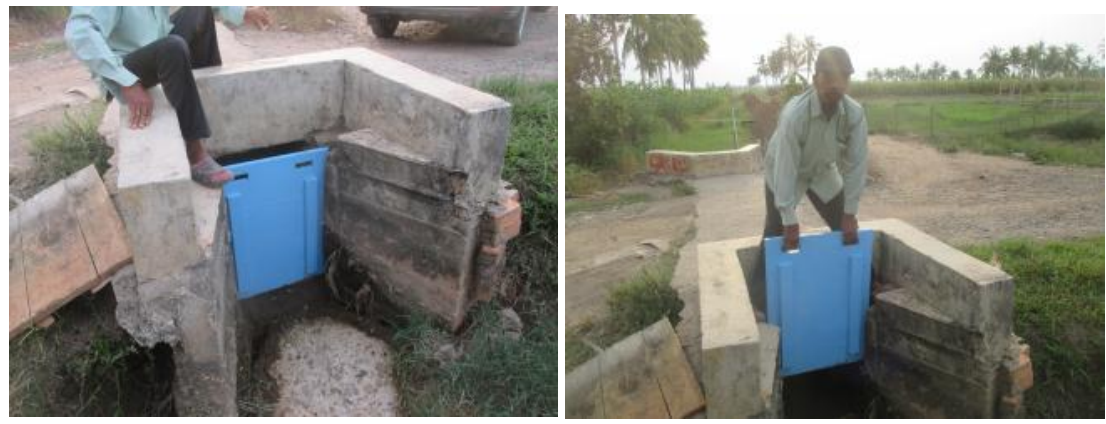

Gambar 6. Pintu sorong bahan papan dan teknik operasi 
Tabel 4. Jadwal operasi pintu rekomendasi dan dilakukan oleh petani

\begin{tabular}{|c|c|c|c|c|}
\hline \multirow{2}{*}{ Fase pertumbuhan } & \multirow{2}{*}{ Waktu } & \multicolumn{3}{|c|}{ Operasi Pintu } \\
\hline & & Pintu Kelep & Stop Log & Pintu Sorong \\
\hline Awal (initial) & 10-20 Maret & Posisi di depan & Atas-Bawah & Buka-tutup \\
\hline Vegetatif & 20-30 April & Posisi di depan & Atas-Bawah & Buka-tutup \\
\hline Generatif & 30-20 Mei & Posisi di depan & Atas & Buka \\
\hline Panen & $>20 \mathrm{Mei}$ & Posisi di depan & Atas & Buka \\
\hline
\end{tabular}

Untuk periode menjelang musim kemarau muka air disaluran harus dipertahankan pada ketingian minimal $80 \mathrm{~cm}$ sd $100 \mathrm{~cm}$. Penelitian Imanudin et al. (2018) di area pasang surut Sugihan menunjukan bila kedalaman muka air di saluran turun sampai $20-30 \mathrm{~cm}$, maka muka air tanah di lahan akan turun melebihi angka $50 \mathrm{~cm}$, dan tanaman jagung sudah menunjukkan gejala kekeringan. Kondisi air tanah dibawah $50 \mathrm{~cm}$ harus sudah ada tambahan irigasi dari luar misalnya dengan pemompaan. Kondisi ini terjadi karena di musim kemarau tidak ada suplai air dari hujan.

\section{Kajian Salinitas}

Hasil analisis laboratorium terkait salinitas air menunjukan angka yang relatif tinggi pada kondisi kemarau 2019. Kandungan salinitas di saluran primer lebih tinggi dibandingkan dengan di saluran tersier. Namun dikarenakan lahan memiliki tofografi yang tinggi maka air asin tidak bisa masuk ke lahan. Ada nilai positif dengan adanya air asin masuk ke saluran berarti mampu menetralisir zat asam yang ada di saluran.. Tabel 5 menunjukkan hasil analisis kadar garam di saluran. Air asin akan hilang terbilas memasuki musim penghujan. Curah hujan di daerah tropis tergolong tinggi, sangat cukup untuk mencucia kadar garam yang terakumulasi di dasar saluran.

Tabel 5. Hasil analisis salinitas air pada saluran primer dan sekunder pada pertengahan ahir bulan tanggal 30 September 2019

\begin{tabular}{llll}
\hline No & Lokasi pengambilan di autlet & $\begin{array}{c}\text { Nilai EC } \\
\mathrm{uS} \mathrm{cm}^{-1}\end{array}$ & $\begin{array}{c}\text { Nilai EC } \\
\mathrm{dS} \mathrm{m} \mathrm{m}^{-1}\end{array}$ \\
\hline 1 & Tersier & 694 & 0.694 \\
2 & Primer & 1244 & 1.244 \\
\hline
\end{tabular}

Menurut Kristiono et al., (2013). Batas kritis tingkat salinitas berdasarkan penurunan hasil pada tanaman kedelai, kacang tanah, dan kacang hijau berturut turut adalah $5 \mathrm{dS} \mathrm{m}^{-1}, 3.2 \mathrm{dS} \mathrm{m}^{-1}$, dan $1-2.65 \mathrm{dS} \mathrm{m}^{-1}$. Tabel 5 Menunjukan hasil analisis kualiatas air di saluran primer dan tersier. Intrusi air asin sudah masuk sampai saluran tersier. Namun demikian nilai EC di saluran tersier masih belum terlalu berbahaya, namun demikian air ini tidak boleh digunakan untuk pengairan. Menurut Peraturan Pemerintah No. 82 Tahun 2001 bila air memiliki kadar salinitas dalam kisaran 1,600 - 3,200 $\mu$ mhos $\mathrm{cm}^{-1}$, bisa dikatakan masuk dalam kategori baik walaupun tidak cocok untuk tanaman peka seperti padi. Sementara itu untuk di saluran primer salinitas cukup tinggi yaitu di angka $1.2 \mathrm{dS} \mathrm{m}^{-1}$. Beberapa tanaman akan menunjukan gejala pertumbuhan terhambat bila mendapatkan suplai air dengan EC diatas $1 \mathrm{dS} \mathrm{m}^{-1}$.

Kandungam garam dalam air dapat mempengaruhi masing-masing pertumbuhan tanaman secara berbeda.

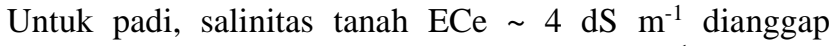
salinitas moderat sementara lebih dari $8 \mathrm{dS} \mathrm{m}^{-1}$ dianggap tinggi. Meningkatnya kadar garam dalam tanah menyebabkan bertambahnya kelarutan $\mathrm{Na}, \mathrm{Ca}, \mathrm{Mg}$ dan $\mathrm{Mn}$ sedangkan kelarutan $\mathrm{K}$ dan $\mathrm{pH}$ tanah cenderung menurun. Pada kawasan dekat pantai sering tampak adanya kristalkristal putih di permukaan tanah yang menunjukan kristal garam. Biasanya tanah bergaram mempunyai $\mathrm{pH}$ kurang dari 5,5 dengan daya hantar listrik (DHL) lebih besar dari 4 mmhos/cm pada suhu $250 \mathrm{C}$ (Suriadikarta, 2005).

Masinga-masing tanaman memiliki respon berbeda terhadap tingkat kandungan $\mathrm{ECw}$ dan ECe. Untuk tanaman jagung, kandungan ECw dan ECe masing-masing sebesar 3.2 mmhos $\mathrm{cm}^{-1}$ dan 2.1 mmhos $\mathrm{cm}^{-1}$ dapat menurunkan produksi jagung sebesar 10\% (Ayers dan Westcot, 1976). Semakin tinggi kandungtan salinitas maka berat kering batang, berat kering daun dan berat kering total tanaman menurun (Hussein et al., 2007). Kondisi ini menunjukan bahwa tanaman jagung tergolong tanaman yang tidak toleran terhadap salinitas.

Konsentrasi $\mathrm{NaCl}$. Hasil analisis statistik pada pengujian ketahanan tanaman jagung dengan pemberian $\mathrm{NaCl}$ menunjukkan bahwa respon panjang akar semakin menurun dengan semakin meningkatnya konsentrasi $\mathrm{NaCl}$ yang diberikan pada media tumbuh tanaman, dengan tingkat penghambatan terhadap pertumbuhan yang berbedabeda. Penghambatan terhadap panjang akar terlihat jelas pada konsentrasi $\mathrm{NaCl} 5 \mathrm{~g} \mathrm{~L}^{-1}$ dibandingkan dengan tanpa pemberian $\mathrm{NaCl}$ (Dahlan et al., 2013). Ditambahkan hasil penelitian Latuharhary et al. (2017) konsentrasi $\mathrm{NaCl}$ berpengaruh nyata terhadap pertumbuhan Jagung varietas Bisma dan Srikandi Kuning. Tingkat ketahanan morfologi Jagung varietas Srikandi Kuning dan Bisma terhadap tingginya konsentrasi $\mathrm{NaCl}$ berbeda. Varietas Srikandi Kuning menunjukkan lebih toleran dibandingkan varietas Bisma. Hasil cekamaan $\mathrm{NaCl}$ terendah terjadi pada konsentrasi 10,000 ppm.

Pada masa awal pertumbuhan tanaman Jagung yaitu fase perkecambahan penelitian Amartani (2019) menunjukkan perlakuan cekaman garam dengan konsentrasi 4000 ppm berbeda tidak nyata dengan perlakuan cekaman garam dengan konsentrasi 0 ppm. Di areal studi belum ditemukan tanaman mengalami gejala keracunan kadar garam. Air asin yang masuk baru sebatas mengisi saluran. Kondisi ini bisa di hindari dengan cara menutup pintu tersier. Kalaupun petani membiarkan terbuka air asin akan bisa dibilas di musim penghujan. Sirkulasi pasang dan surut dengan operasi pintu terbuka selama periode November-Februari mampu membersihkan saluran.

\section{SIMPULAN}

Faktor pembatas utama di lahan rawa pasang surut dalam rangka usaha budidaya jagung adalah kesuburan tanah yang meliputi tingkat kemasaman tinggi, rendah unsur hara makro yang meliputi Nitrogen, Phospour dan Kalium. Upaya perbaikan bisa dilakukan dengan peberian pupuk dan pengapuran. Komponen iklim dan hidrologi 
yang bisa menjadi pembatas utama adalah meliputi curah hujan, dan fluktuasi muka air di saluran.

Pola pendekatan aplikasi teknologi adalah melalui modifikasi dan adaptasi lingkungan. Pemilihan teknologi harus berdasarkan pertimbangan teknis (mudah), sosial (diterima), dan murah.

Pengendalian muka air tanah merupakan kunci utama untuk menjaga kondisi lahan bisa diusahakan pertanian pangan. Air tanah dijaga berada diatas lapisan pirit. Kalaupun terjadi oksidasi firit bila musim kemaran panjang, maka diperlukan sistem Tata Air Mikro untuk mempercepat proses pencucian lahan. Tata air mikro denga jarak antar saluran 8m, dan kedalaman $20 \mathrm{~cm}$ sudah memadai untuk budidaya tanaman jagung.

Pada tanah tipologi $\mathrm{C}$ yang dekat laut, bahaya salinitas terjadi bila musim kemarau lebih dari empat bulan. Intrusi air asin terjadi mulai bulan September, sehingga operasi pintu air mulai bulan Juli sudah harus ditutup permanen. Tujuan utama adalan menahan air hujan sebanyak mungkin, karena curah hujan sejak Agustus berada dibawah $50 \mathrm{~mm}$.

\section{DAFTAR PUSTAKA}

Amartani, K. 2019. Respon Perkecambahan Benih Jagung (Zea mays. L) Pada Kondisi Cekaman Garam. Agrosaintek Jurnal Ilmu dan Teknologi Pertanian, 3(1):9-14

Annisa, W. 2012. Peran Biocar Sekam Padi terhadap Emisi Metana di Lahan Rawa Pasang Surut. Prosiding Seminar Nasional Inovasi Teknologi Pertanian 1441 Banjarbaru, 20 Juli 2016.

Armanto, M.E., M.A. Adzemi, E. Wildayana and M.S. Imanudin. 2013. Land Evaluation for Paddy Cultivation in the Reclaimed Tidal Lowland in Delta Saleh, South Sumatra Indonesia. Journal of Sustainability and Management, 8(1): 32-42.

Ayers, R.S. and D.W. Westcot. 1976. Water quality for agriculture. Rome: Food and Agriculture of Organization of the United Nation.

Bakri, M.S. Imanudin and S.M. Bernas. 2015. Water retention option of drainage system for dry season corn cultivation at tidal lowland area. Journal Agrivita, 37(3): 237-246.

CNBC Indonesia. 2020. RI Kaji Impor Jagung 200 Ribu Ton di $2020 \quad$ di unduh https://www.cnbcindonesia.com/news/202002051 91714-4-135647/ri-kaji-impor-jagung-200-ributon-di-2020

Dachlan, A., N. Kasim dan A.K. Sari. 2013. Uji Ketahanan Salinitas Beberapa Varietas Jagung (Zea mays L.) Dengan Menggunakan Agen Seleksi NaCl. Biogenesis: Jurnal Ilmiah Biologi, 1(1): 9-17

Dalhem, K., S. Engblom, P. Stén, and P. Österholma. 2019. Subsurface hydro chemical precision treatment of a coastal acid sulfate soil. Applied Geochemistry, 100(2019): 352-362.

Gao, X., Z. Huo, Z. Qu, X. Xu, G. Huang and T.S. Steenhuis. 2017. Modeling contribution of shallow groundwater to evapotranspiration and yield of maize in an arid area. Scientific Reports, 7(2017): 43122. Published 2017 Feb 21. Doi: 10.1038/srep43122.

Hadi, R. 2004. Teknik pencegahan oksidasi pirit dengan tata air mikro pada usahat tani jagung di lahan pasang surut. Buletin Teknik Pertanian, 9(2): 61-65.

Hafiyyan, Q., Marsudi dan Nurhayati. 2017. Dinamika aliran air tanah pada lahan rawa pasang surut. JeLAST: Jurnal PWK, Laut, Sipil, Tambang, 4(4): $1-11$.

http://ditjenpkh.pertanian.go.id/pasokan-jagung-untukpakan-awal-tahun-2020-aman.

Hussein, M.M., L.K. Balbaa and M.S. Gaballah. 2007. Salicylic acid and salinity effect on growth of maize plants. Research Journal of Agriculture and Biological Science, 3(4): 321-328.

Imanudin, M.S., E. Armanto and R.H. Susanto. 2012. Effect of water management Improvement on Soil Nutrient Content, Iron and Alumunium Solubility at Tidal Lowland Areas. Asia Agriculture and Animal ISSN 2212-6708 APCBEE Procedia (2012) available Sciverse Science Direct.

Imanudin, M.S., E. Armanto, R.H. Susanto and S.M. Bernas. 2010. Water Table Fluctuation in Tidal Lowland for Developing Agricultural Water Management Strategies. Journal of Tropical Soils, 15(3): 277282.

Imanudin, M.S., Bakri, M.E. Armanto, B.I. Setiawan and S.N.P. Ratmini. 2018. Land and Water Management Option of Tidal Lowland Reclamation Area to Support Rice Production (A Case Study in Delta Sugihan Kanan of South Sumatra Indonesia). Journal of Wetlands Environmental Management, 6(2): 93-111.

Imanudin, M.S., M.E. Armanto and Bakri. 2019. Determination of planting time of watermelon under a shallow Groundwater table in tidal lowland agriculture areas of South Sumatra, Indonesia. Irrigation and Drainage Journal, 68(3): 488-495.

Imanudin, M.S., R.H. Susanto and D. Budianta. 2016. ElNino Effect on Water Management Objective in Tidal Lowland Reclamation Areas (Adaptation Model for Corn) di sampaikan dalam seminar internasional $2^{\text {nd }}$ World Irrigation Forum 6-8 November 2016. Chiang Mai-Thailand ISBN 97881-89610-22-7.

Imanudin, M.S., S.J. Priatna, E. Wildayana and M.E. Armanto. 2017. Variability of ground water table and some soil chemical characteristic of tertiary block of tidal lowland agrivulture South Sumatera Indonesia. Sains Tanah - Journal of Soil Science and Agroclimatology, 14(1): 1-6.

Indriyati, L.T. dan I. Anas. 2013. Jerapan nitrogen-urine oleh zeolit dan pengaruhnya terhadap pertumbuhan tanaman jagung (zea mays L.). Jurnal Ilmu Tanah dan Lingkungan, 15(2): 84-90. 
Katerji, N., J.W. van Hoorn, A. Hamdy, F. Karam and M. Mastrorilli. 2003. Effect of Salinity on emergence and on Water Stress and Early Seedling Growth of Sunflower and Maize. Agricultural Water Management, 26(1-2): 81-91,. http://dx.doi.org/10.1016/0378-3774(94)90026-4.

[Kementan] Kementerian Pertanian. 2020. Pasokan Jagung Untuk Pakan Awal Tahun 2020 Aman di unduh.

Kristiono, A., R.D. Purwaningrahayu dan A. Taufiq. 2013. Respons tanaman kedelai, kacang tanah, dan kacang hijau terhadap cekaman salinitas. Buletin Palawija, 26: 45-60.

Latuharhary, R.A. dan T.B. Saputro. 2017. Respon Morfologi Tanaman Jagung (Zea mays) Varietas Bisma dan Srikandi Kuning pada Kondisi Cekaman Salinitas Tinggi. Jurnal Sains dan Seni ITS, 6(2): 2337-3520.

Maftu'ah, E. dan A. Susilawati. 2018. Bioleaching untuk meningkatkan produktivitas lahan sulfat masam aktual untuk tanaman padi. Berita Biologi: Jurnal Ilmu-ilmu Hayati, 17(3): 253-264.

Materechera, S.A. 2011. Soil Salinity in Irrigated fields used for urban agriculture under a semi-arid environment of South Africa. African Journal of Agricultural Research, 6(16): 3747-3754. www.academicjournals.org/AJAR.

Mensegue, H.R.V., A.J. Degioanni and J.M. Cisneros. 2015. Estimating shallow water table contribution to soybean water use in argentina. European Scientific Journal, 11(14): 23-40.

Nurdin. 2012. Penilaian kesesuaian lahan untuk pengembangan jagung di kebun percobaan Dulamayo Kabupaten Gorontalo. Jurnal Perkebunan \& Lahan Tropika, 2(1): 35-44.

Republik Indonesia, Peraturan Pemerintah No. 82 Tahun 2001 Tentang Pengelolaan Kualitas Air dan Pengendalian Pencemaran Air.

Rizzo, G., J.I.R. Edreira, S.V. Archontoulis, H.S. Yang and P. Grassini. 2018. Do shallow water tables contribute to high and stable maize yields in the US Corn Belt?. Global Food Security, 18(2018): 27-34.

Runtunuwu, E., B. Kartiwa, Kharmilasari, Sudarman, Kurmen, W. Nugroho dan A. Firmansyah. 2011. Dinamika Elevasi Muka Air pada Lahan dan Saluran di Lahan Gambut. Riset Geologi dan Pertambangan, 21(2):63-74.

Sagala, D. 2010. Peningkatan pH-tanah masam di lahan rawa pasang surut pada berbagai dosis kapur. Jurnal Agroqua: Media Informasi Agronomi dan Budidaya Perairan, $\quad 8(2)$ : $1-5$. https://doi.org/10.32663/ja.v8i2.39.
Schultz, B., R.H. Susanto, F.X. Suryadi and A.S. Waskito. 2015. Analysis of water management in reclaimed tidal lowlands of Indonesia. Experiences in the Telang I Scheme, Musi Delta, South Sumatra. In Kop J, Ravensteijn W, Kop K (eds). Irrigation Revisited. An Anthology of Indonesian-Dutch Cooperation 1965-2014. Eburon: Delft, the Netherlands/Jakarta, Indonesia.

Setiawan, B., S. Gafur dan T. Abdurrahman. 2019. Biochar Application of Rice Husk and Shellfish Flour to Increase Soybean Crop Productivity in Acid Sulphate Soil. AGROVIGOR, 12(2): 70-76.

Shamshuddin, J., E. Azura, M.A.R.S. Shazana, C.I. Fauziah, Q.A. Panhwar and U.A. Naher. 2014. Properties and Management of Acid Sulfate Soils in Southeast Asia for Sustainable Cultivation of Rice, Oil Palm, and Cocoa. Advances in Agronomy, Volume 124.

Shaon, K.D. and K.D. Suvo. 2015. Acid Sulphate Soil: Management Strategy for Soil Health and Productivity. Popular Kheti, 3(2): 2-7.

Sosiawan, H., B. Kartiwa, W.T. Nugroho dan H. Syahbuddin. 2017. Variasi temporal dan spasial tinggi muka air tanah gambut lokasi demplot icctf jabiren Kalimantan Tengah. Jurnal Tanah dan Air, 14(2) 68-82.

Suprianto, H., E. Ravaie, S. Irianto, R. Susanto, B. Schultz, F. Suryadi and A. Eelaart. (2009). Land and water management tidal lowlands: Experiences in Telang and Saleh, South Sumatra. Irrigation and Drainage, 59(3): 317-335.

Suriadikarta, D.A. 2005. Pengelolaan lahan sulfat masam untuk usaha pertanian. J. Litbang Pertanian, 24:36-45.

Widyantika, S.D. dan S. Priyono. 2019. Effect of High Doses of Rice Husk Biochar on Soil Physical Properties and Growth of Maize on a Typic Kanhapludult. Jurnal Tanah dan Sumberdaya Lahan, 6(1): 1157-1163.

Zulputra. 2019. Pengaruh pemberian biochar arang sekam padi terhadap pertumbuhan dan hasil tanaman kacang panjang (Vigna sinensis L.). Jurnal Sungkai, 7(2): 81-90.

Zuraida, R. dan R. Galib. 2010. Sistem Usahatani Jagung pada Lahan Pasang Surut di Kalimantan Selatan (Kasus di Desa Simpang Jaya Kecamatan Wanaraya Kabupaten Barito kuala). Prosiding Pekan Serealia Nasional. ISBN : 978-979-894029-3. Pp. 532-536. 